Check for updates

Cite this: RSC Adv., 2017, 7, 23742

\title{
Oxidation modification of Ru-based catalyst for acetylene hydrochlorination $\uparrow$
}

\author{
Baochang Man, ${ }^{\mathrm{ab}}$ Haiyang Zhang, (D) *ab Jinli Zhang, ${ }^{\star a c}$ Xing Li, ${ }^{\mathrm{ab}} \mathrm{Na} \mathrm{Xu},{ }^{\text {ab }}$ Hui Dai, ${ }^{\mathrm{c}}$ \\ Mingyuan Zhu ${ }^{\mathrm{ab}}$ and Bin Dai ${ }^{\mathrm{ab}}$
}

To prepare Ru-based catalysts with improved performance, activated carbon (AC) and Ru species were modified with nitric acid by different manners, and the resulting catalysts were characterized via a series of techniques. It was indicated that the oxidation of AC alone did not enhance the activity of the catalyst, but the modification enhanced the interaction between the oxygenated functional groups and $\mathrm{Ru}$ species, and the interaction could improve the catalytic performance of the catalysts. A Ru-O/AC-O catalyst prepared by the modification of active components, followed by the modification of $\mathrm{AC}$ exhibited outstanding activity and stability with an initial $\mathrm{C}_{2} \mathrm{H}_{2}$ conversion of $99.6 \%$ at $180{ }^{\circ} \mathrm{C}$ and a $\mathrm{C}_{2} \mathrm{H}_{2}$ space velocity of $180 \mathrm{~h}^{-1}$. The modification strengthened the adsorption of reactants, and also ensured the good dispersal of $\mathrm{Ru}$ species and augmented the amount of high-valence active species, consequently enhancing the catalytic activity.

Received 25th January 2017

Accepted 17th April 2017

DOI: 10.1039/c7ra01121k

rsc.li/rsc-advances

$50 \mathrm{~h}^{-1}$ ). Zhang et $a .^{6}{ }^{6}$ synthesized ternary $\mathrm{Au}-\mathrm{Co}(\mathrm{III})-\mathrm{Cu}(\mathrm{II})$

\section{Introduction}

Vinyl chloride monomer (VCM) is commonly used to synthesize polyvinyl chloride, which is the second most widely used general resin. The hydrochlorination of acetylene is an essential process for manufacturing VCM in countries with rich coal resources. Activated carbon-supported $\mathrm{HgCl}_{2}$ is used as an industrial catalyst in this process; however, $\mathrm{HgCl}_{2}$ is highly toxic and sublimates easily, resulting in serious environmental and health risks. ${ }^{1-4}$ In addition, in the year 2013, more than 140 countries signed "Minamata Convention on Mercury" treaty, which aims to control the worldwide consumption of mercury. ${ }^{5}$ Therefore, the development of mercury-free catalysts for producing PVC has attracted considerable attention. ${ }^{6-9}$ The main metals investigated for mercury-free catalysts are $\mathrm{Au}, \mathbf{4 , 6 , 1 0}$ $\mathrm{Pd},{ }^{8,11} \mathrm{Ru},{ }^{12-14} \mathrm{La},{ }^{15}$ and $\mathrm{Ba}^{16}$ It is widely accepted that among these catalysts, $\mathrm{Au}$ catalysts are superior in terms of initial activity. For example, Shen et al. ${ }^{9}$ reported that the Au1Cu5/C (w/w, total metal amount of $3 \mathrm{wt} \%$ ) catalyst promotes $100 \%$ acetylene conversion and features a stability exceeding $200 \mathrm{~h}$ in on stream reactions under optimized conditions (temperature, $160{ }^{\circ} \mathrm{C} ; V_{\mathrm{HCl}} / V_{\mathrm{C}_{2} \mathrm{H}_{2}}, 1.15$; total gas hourly space velocity (GHSV),

${ }^{a}$ School of Chemistry and Chemical Engineering of Shihezi University, Shihezi, Xinjiang 832000, PR China. E-mail: zhy198722@163.com; zhangjinli@tju.edu.cn; Fax: +86993-2057210; Tel: +86-993-2057-277

${ }^{b}$ Key Laboratory for Green Processing of Chemical Engineering of Xinjiang Bingtuan, Shihezi, Xinjiang 832000, PR China

${ }^{c}$ School of Chemical Engineering \& Technology, Tianjin University, Tianjin 300072, PR China

$\dagger$ Electronic supplementary information (ESI) available. See DOI: $10.1039 / \mathrm{c} 7 \mathrm{ra} 01121 \mathrm{k}$ catalysts and found that over the optimal catalyst Au1Co(III) $3 \mathrm{Cu}$ (II) $1 / \mathrm{SAC}$, the acetylene conversion reached $99.7 \%$ and the selectivity to VCM was $99.9 \%$ within $48 \mathrm{~h}$ under the reaction conditions of $150{ }^{\circ} \mathrm{C}, V_{\mathrm{HCl}} / V_{\mathrm{C}_{2} \mathrm{H}_{2}}$ ratio of 1.15 , and $\operatorname{GHSV}\left(\mathrm{C}_{2} \mathrm{H}_{2}\right)$ of $360 \mathrm{~h}^{-1}$. Wei et al. ${ }^{17}$ prepared $\mathrm{Au}-\mathrm{Bi} / \mathrm{AC}$ catalysts and found that the synergistic effect between $\mathrm{Bi}$ and $\mathrm{Au}$ stabilized the $\mathrm{Au}^{+}$ by inhibiting the reduction to metallic $\mathrm{Au}$, and over the $\mathrm{Au}-\mathrm{Bi}$ / $\mathrm{AC}(0.3 \mathrm{wt} \% \mathrm{Au}, 0.95 \mathrm{wt} \% \mathrm{Bi})$ catalyst, the acetylene conversion reached $85 \%$ within $10 \mathrm{~h}$ under the reaction conditions of $180^{\circ} \mathrm{C}, V_{\mathrm{HCl}} / V_{\mathrm{C}_{2} \mathrm{H}_{2}}$ ratio of 1.10 , and $\operatorname{GHSV}\left(\mathrm{C}_{2} \mathrm{H}_{2}\right)$ of $600 \mathrm{~h}^{-1}$. G. J. Hutchings reported that the catalytic activity for the hydrochlorination of acetylene to vinyl chloride correlated significantly with the standard reduction potential of the metal cation for supported metal chloride catalysts. ${ }^{2}$ The standard potential of $\mathrm{Ru}^{4+}\left(E\left(\mathrm{Ru}^{4+}\right)\right)$ is $1.12 \mathrm{~V}$, which is higher than that of $\mathrm{Hg}^{2+}$ $\left(E\left(\mathrm{Hg}^{2+}\right)\right)$ at $0.851 \mathrm{~V},{ }^{2}$ while the standard potential of $\mathrm{Ru}^{3+}$ is $0.455 \mathrm{~V},{ }^{18,19}$ which is lower than that of $\mathrm{Hg}^{2+}$. Moreover, the price of $\mathrm{Ru}$ is much lower than that of $\mathrm{Au}$; therefore, $\mathrm{Ru}$ may also be an alternative candidate catalyst for acetylene hydrochlorination.

$\mathrm{Ru}$-based catalysts commonly feature AC as a carrier owing to its large specific surface area and rich pore structure. In addition, AC can be modified by different treatment processes. ${ }^{20-22}$ The surface chemistry of the support material is an extremely important factor that affects both the preparation of the catalyst and its performance. ${ }^{23-25} \mathrm{Xu}$ et al. reported that AC was consecutively treated by nitration, amination, and pyridine modification, and that the Ru/AC-NHN catalyst showed best catalytic activity with a $\mathrm{C}_{2} \mathrm{H}_{2}$ conversion of $93.0 \%$ and selectivity to VCM of 99.9\%. ${ }^{26} \mathrm{Li}$ et al. synthesized a metal-free catalyst SiC@N-C via growing a $\mathrm{N}-\mathrm{C}$ layer out of preshaped SiC granules. The catalyst 
exhibited good heat conductivity, mechanical strength, and chemical stability and showed stable catalytic performance during $150 \mathrm{~h}$ with a $\mathrm{C}_{2} \mathrm{H}_{2}$ conversion of $80 \%$ and a selectivity to VCM of $98 \%$ at $200{ }^{\circ} \mathrm{C}^{27}$ Zhao et al. modified AC with melamine, and the $\mathrm{N}$-doped $\mathrm{AC}$ enhanced the activity of $\mathrm{Ru} / \mathrm{AC}-\mathrm{N}$ catalysts under the reaction temperature of $250{ }^{\circ} \mathrm{C}$ and a total liquid hourly space velocity of 1,2-dichloroethane (EDC) of $0.2 \mathrm{~h}^{-1}$ in the reaction of $\mathrm{EDC}$ and $\mathrm{C}_{2} \mathrm{H}_{2} \cdot{ }^{28} \mathrm{Li}$ et al. ${ }^{29}$ reported that $\mathrm{Ru}$ catalysts deposited inside CNTs' channels exhibited optimal catalytic activity, with an acetylene conversion of $95.0 \%$ and selectivity to VCM of $99.9 \%$ after $10 \mathrm{~h}$ on stream under the conditions of $170{ }^{\circ} \mathrm{C}$ and GHSV $\left(\mathrm{C}_{2} \mathrm{H}_{2}\right)$ of $90 \mathrm{~h}^{-1}$. Modification of the properties of the active species is also an effective method to regulate the catalytic performance of catalysts. Jin et al. ${ }^{30}$ reported that acetylene conversion reached the highest rate of $93.4 \%$ under the conditions of $170{ }^{\circ} \mathrm{C}, \operatorname{GHSV}\left(\mathrm{C}_{2} \mathrm{H}_{2}\right)$ of $180 \mathrm{~h}^{-1}$, and a feed volume ratio $V\left(\mathrm{HCl}_{1}\right) / V\left(\mathrm{C}_{2} \mathrm{H}_{2}\right)$ of 1.1 over $\mathrm{Ru}-\mathrm{K} / \mathrm{SAC}$ catalysts. $\mathrm{Pu}$ et $a l .{ }^{31}$ reported that a $\mathrm{Ru} / \mathrm{SAC}-\mathrm{C} 300$ catalyst promoted a stable acetylene conversion at $96.5 \%$ in $48 \mathrm{~h}$ at $170{ }^{\circ} \mathrm{C}$ and a $\mathrm{GHSV}\left(\mathrm{C}_{2^{-}}\right.$ $\mathrm{H}_{2}$ ) of $180 \mathrm{~h}^{-1}$. Previously, we reported that the addition of Co species to a Ru-based catalyst increased the amount of active species and promoted the catalytic performance of the catalyst Ru1Co3/SAC (spherically activated carbon) with an acetylene conversion of $95 \%$ during a $48 \mathrm{~h}$ test at $170{ }^{\circ} \mathrm{C}, \mathrm{a} \mathrm{C}_{2} \mathrm{H}_{2}$ gas hourly space velocity (GHSV) of $180 \mathrm{~h}^{-1}$, and a $V_{\mathrm{HCl}} / V_{\mathrm{C}_{2} \mathrm{H}_{2}}$ of $1.1 .^{13}$ Thereafter, we reported that the addition of $\mathrm{Cu}$ (II) and $\mathrm{Co}$ (III) augmented the amount of $\mathrm{RuO}_{2}$ active species, and the $0.1 \mathrm{wt} \%$ Ru1Co(III)3Cu(II)1/SAC catalyst exhibited optimal activity, with a $\mathrm{C}_{2} \mathrm{H}_{2}$ conversion of $99.0 \% .{ }^{32}$ However, the catalytic performance of Ru-based catalysts is still not as good as that of $\mathrm{Au}$ based catalysts under the same reaction conditions.

Nevertheless, the previous preparation processes of the $\mathrm{Ru}^{-}$ based catalysts are tedious. In addition, concerning the economics and the problem that the amount of $\operatorname{RuO}_{x}(x \geq 2)$ active species needs to be further improved to enhance the catalytic activity of the Ru-based catalysts, we prepared oxidized $\mathrm{Ru}$ catalysts by different modification methods in this study, and we also investigated in detail the effect of the modification method used on the catalytic performance. The results indicate that the economical $\mathrm{Ru}-\mathrm{O} / \mathrm{AC}-\mathrm{O}$ catalyst could give favorable performance and that the catalyst may be promising for future applications.

\section{Experimental}

\subsection{Materials}

AC (coconut carbon, 40-60 mesh, neutral) was purchased from Tangshan United Carbon Technology Co., Ltd. $\mathrm{RuCl}_{3}(48.7 \%$ $\mathrm{Ru})$ was purchased from Tianjin Fengchuan Chemical Reagent Co., Ltd. All the other chemicals and materials were commercially available and were used without further purification.

\subsection{Catalyst preparation}

AC was stirred in $\mathrm{HCl}(36 \mathrm{wt} \%)$ solution at $70{ }^{\circ} \mathrm{C}$ for $5 \mathrm{~h}$ and then filtered and washed to neutral $\mathrm{pH}$ value with deionized water, followed by desiccation at $140{ }^{\circ} \mathrm{C}$ for $18 \mathrm{~h}$. The obtained sample was labeled as AC and used as the initial material for the further modification. Pretreated AC was stirred in $20 \mathrm{~mL}$ nitric acid $\left(0.94 \mathrm{~mol} \mathrm{~L}^{-1}\right)$ solution at ambient temperature for $5 \mathrm{~h}$ and then filtered and washed to neutral $\mathrm{pH}$ with deionized water, followed by desiccation at $140{ }^{\circ} \mathrm{C}$ for $18 \mathrm{~h}$. The resultant sample was denoted as AC-O.

All the Ru-based catalysts were prepared using an incipient wetness impregnation method. ${ }^{\mathbf{4 , 1 0 , 1 3}} \mathrm{RuCl}_{3}(0.064 \mathrm{~g})$ was dissolved in deionized water and added dropwise to AC-O (3.0 g) with agitated stirring, then the mixture was dipped for $24 \mathrm{~h}$ at room temperature, filtered, and washed to neutral $\mathrm{pH}$ with deionized water, followed by evaporation at $140{ }^{\circ} \mathrm{C}$ for $24 \mathrm{~h}$. The sample was termed $\mathrm{Ru} / \mathrm{AC}-\mathrm{O}$. The $\mathrm{Ru} / \mathrm{AC}$ catalyst was prepared by impregnating the $\mathrm{AC}$ carrier $(3.0 \mathrm{~g})$ with $\mathrm{a} \mathrm{RuCl}_{3}(0.064 \mathrm{~g})$ aqueous solution under stirring; then the mixture was dipped for $24 \mathrm{~h}$ at ambient temperature, filtered, then the product was washed to neutral $\mathrm{pH}$ with deionized water. The obtained mixture was desiccated at $140{ }^{\circ} \mathrm{C}$ for $24 \mathrm{~h}$ to obtain the $\mathrm{Ru} / \mathrm{AC}$ catalyst. For the synthesis of ( $\mathrm{Ru} / \mathrm{AC})-\mathrm{O}$, the $\mathrm{Ru} / \mathrm{AC}$ catalyst $(3.0 \mathrm{~g})$ was added to nitric acid $\left(20 \mathrm{~mL}, 0.94 \mathrm{~mol} \mathrm{~L}^{-1}\right)$ solution and refluxed at $80{ }^{\circ} \mathrm{C}$ for $24 \mathrm{~h}$. The solution was then filtered and the product was washed to neutral $\mathrm{pH}$ with deionized water, followed by evaporation at $140{ }^{\circ} \mathrm{C}$ for $24 \mathrm{~h}$, and the catalyst was named as ( $\mathrm{Ru} / \mathrm{AC})-\mathrm{O}$. For the synthesis of $\mathrm{Ru}-\mathrm{O} / \mathrm{AC}-\mathrm{O}$, nitric acid $\left(20 \mathrm{~mL}, 0.94 \mathrm{~mol} \mathrm{~L}^{-1}\right)$ solution was added to the $\mathrm{RuCl}_{3}$ aqueous solution with stirring at $80^{\circ} \mathrm{C}$ for $24 \mathrm{~h}$, then $\mathrm{AC}-\mathrm{O}(3.0$ $\mathrm{g}$ ) was added to the solution with stirring for another $24 \mathrm{~h}$. The mixture was filtered and the product was washed to neutral $\mathrm{pH}$ with deionized water, followed by evaporation at $140{ }^{\circ} \mathrm{C}$ for $24 \mathrm{~h}$ to prepare $\mathrm{Ru}-\mathrm{O} / \mathrm{AC}-\mathrm{O}$. The brief preparation procedures are shown in Fig. S1. $\uparrow$ The amount of Ru loading in all the Ru-based catalysts was fixed at $1.0 \mathrm{wt} \%$.

\subsection{Catalyst characterization}

Fourier transform infrared (FT-IR) spectroscopy was obtained using a Bruker Vertex70 FT-IR spectrophotometer with the resolution of $4 \mathrm{~cm}^{-1}$ and the scanning times of 64 to identify the correlated bond vibrations of the Ru-based catalysts.

Low-temperature $\mathrm{N}_{2}$ adsorption-desorption experiments were conducted with a Micromeritics ASAP 2020C instrument. The samples were first degassed at $150{ }^{\circ} \mathrm{C}$ for $6 \mathrm{~h}$ and then analyzed at $-196{ }^{\circ} \mathrm{C}$ via liquid nitrogen adsorption.

Thermogravimetric analysis (TGA) of the catalysts was conducted with a TG-DSC simultaneous thermal analyzer (NETZSCH STA 449F3, Germany) under an air atmosphere at a flow rate of 30 $\mathrm{mL} \min ^{-1}$, and with the temperature increasing from ambient temperature to $800{ }^{\circ} \mathrm{C}$ at a heating rate of $10{ }^{\circ} \mathrm{C} \mathrm{min}^{-1}$.

Temperature-programmed reduction (TPR) and temperatureprogrammed desorption (TPD) experiments were conducted with a Quantachrome AMI-90 instrument. For the TPR profiles, the samples $(0.1 \mathrm{~g})$ were first treated with $\mathrm{N}_{2}$ gas for $1 \mathrm{~h}$ at $80^{\circ} \mathrm{C}$. After cooling, the temperature was then increased from $25^{\circ} \mathrm{C}$ to $850{ }^{\circ} \mathrm{C}$ at a heating rate of $10{ }^{\circ} \mathrm{C} \mathrm{min}^{-1}$ under a $10 \% \mathrm{H}_{2} / \mathrm{Ar}(45$ $\mathrm{mL} \min ^{-1}$ ) atmosphere. For the $\mathrm{C}_{2} \mathrm{H}_{2}$-/ $\mathrm{HCl}$-TPD experiments, the samples $(0.1 \mathrm{~g})$ were first pretreated under a $\mathrm{C}_{2} \mathrm{H}_{2}$ or $\mathrm{HCl}$ atmosphere for $6 \mathrm{~h}$ at the reaction temperature. Then, high- 
purity $\mathrm{N}_{2}\left(45 \mathrm{~mL} \min ^{-1}\right.$ ) was passed through the sample for $20 \mathrm{~min}$ at $100{ }^{\circ} \mathrm{C}$. After cooling, the temperature was increased from $25{ }^{\circ} \mathrm{C}$ to $500{ }^{\circ} \mathrm{C}$ to record the profiles. As for the CO-TPD experiments, the sample $(0.1 \mathrm{~g})$ was first reduced under a $10 \%$ $\mathrm{H}_{2} / \mathrm{Ar}\left(30 \mathrm{~mL} \mathrm{~min}^{-1}\right)$ atmosphere at $300{ }^{\circ} \mathrm{C}$ for $2 \mathrm{~h}$. After cooling, $250 \mu \mathrm{L}$ pulses of $10 \% \mathrm{CO} / \mathrm{He}$ were passed through the sample, then the $\mathrm{CO}$ uptake profile was recorded and the dispersion of $\mathrm{Ru}$ in the Ru-based catalysts was calculated.

X-ray photoelectron spectroscopy (XPS) analysis was performed with an Axis Ultra spectrometer equipped with a monochromatized AlK $\alpha$ X-ray source $(225 \mathrm{~W})$. The spectral regions of Ru3p3 and C1s for the catalysts were recorded, and the C1s peak $(284.6 \mathrm{eV})$ was adopted for the calibration of the spectra.

Transmission electron microscopy (TEM) images were taken using a JEM2010 electron microscope working at $200 \mathrm{kV}$. First, the powders of the samples were dispersed in ethanol solution and then were supported on carbon-film-coated copper grids to obtain the images.

X-ray diffraction (XRD) data were collected using a Bruker D8 (Germany) advanced $\mathrm{X}$-ray diffractometer with $\mathrm{CuK} \alpha$ irradiation $(\lambda=1.5406 \AA)$ at $40 \mathrm{~mA}$ and $40 \mathrm{kV}$ in the wide angles of $10-90^{\circ}$.

\subsection{Catalytic performance tests}

The catalytic performance tests were performed in a fixed-bed reactor (i.d. $10 \mathrm{~mm}$ ), which was purged with nitrogen prior to the catalytic reaction to remove air and water from the reaction system. Hydrogen chloride $\left(20 \mathrm{~mL} \mathrm{~min}^{-1}\right)$ was introduced into the reactor to activate the catalyst before the reaction was started, and the temperature of the reactor was heated to $180{ }^{\circ} \mathrm{C}$. Then, $\mathrm{C}_{2} \mathrm{H}_{2}\left(5.9 \mathrm{~mL} \mathrm{~min}{ }^{-1}\right)$ and $\mathrm{HCl}\left(9.0 \mathrm{~mL} \mathrm{~min}^{-1}\right)$ were then fed through the filter with a $\operatorname{GHSV}\left(\mathrm{C}_{2} \mathrm{H}_{2}\right)$ of $180 \mathrm{~h}^{-1}(2 \mathrm{~mL}$ catalyst) at a temperature of $180{ }^{\circ} \mathrm{C}$. Under certain conditions, the flow rate of acetylene and the size of catalyst were changed to investigate the effect of mass transfer on the catalytic activity, and the results indicated that the effect of the external diffusion was eliminated at the $\mathrm{C}_{2} \mathrm{H}_{2}$ flow rate range of 5-40 $\mathrm{mL} \mathrm{min}^{-1}$; the reaction rate was not limited by the internal mass transport within the $0.180-1.180 \mathrm{~mm}$ (16-80 mesh) grain size range. The gas phase products were first passed through an absorption bottle containing sodium hydroxide solution, and then the reaction products were analyzed by gas chromatography (GC2014C).

\section{Results and discussion}

\subsection{Catalytic performance of the Ru-based catalysts}

To determine the optimal oxidation modification procedure for the AC-supported Ru-based catalysts, four different modified catalysts, $\mathrm{Ru} / \mathrm{AC}, \mathrm{Ru} / \mathrm{AC}-\mathrm{O},(\mathrm{Ru} / \mathrm{AC})-\mathrm{O}$, and $\mathrm{Ru}-\mathrm{O} / \mathrm{AC}-\mathrm{O}$, were assessed for acetylene hydrochlorination. Fig. 1 shows the catalytic performance of the catalysts.

The Ru-free supports (AC, AC-O) showed relatively low activity, with acetylene conversions of $12.0 \%$ and $11.0 \%$, respectively. $\mathrm{Ru} / \mathrm{AC}$ exhibited an initial acetylene conversion of ca. $62.0 \%$. Compared with the original $\mathrm{Ru} / \mathrm{AC}$ catalyst, the catalytic activities of the oxidized catalysts were improved in the
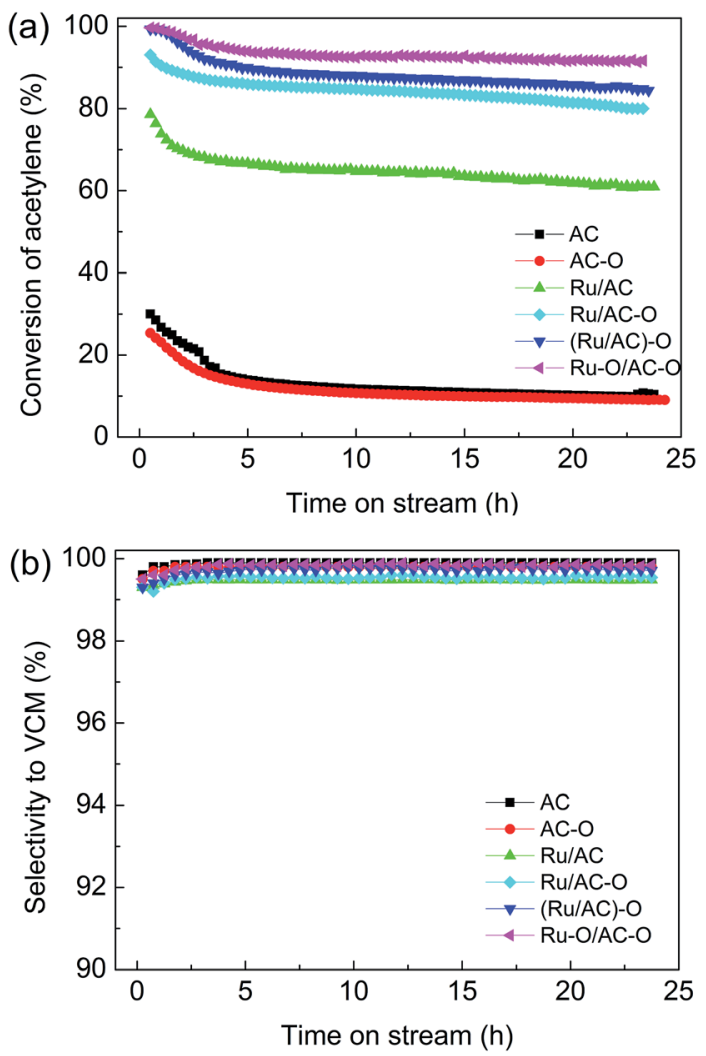

Fig. 1 Effect of oxidation modification on the catalytic performance of Ru-based catalysts. Reaction conditions: temperature $=180{ }^{\circ} \mathrm{C}$, $\operatorname{GHSV}\left(\mathrm{C}_{2} \mathrm{H}_{2}\right)=180 \mathrm{~h}^{-1}$, and $V_{\mathrm{HCl}} / V_{\mathrm{C}_{2} \mathrm{H}_{2}}=1.15: 1$.

order of $\mathrm{Ru}-\mathrm{O} / \mathrm{AC}-\mathrm{O}>(\mathrm{Ru} / \mathrm{AC})-\mathrm{O}>\mathrm{Ru} / \mathrm{AC}-\mathrm{O}>\mathrm{Ru} / \mathrm{AC}$ (Fig. 1a), with the highest acetylene conversion of $93.0 \%$ being achieved over the $\mathrm{Ru}-\mathrm{O} / \mathrm{AC}-\mathrm{O}$ catalyst and with no obvious decrease in activity after $24 \mathrm{~h}$ of reaction. This indicated that the oxidation modification of activated carbon alone does not improve the activity of the catalyst, and that possibly the interaction between oxygenated functional groups and $\mathrm{Ru}$ species can enhance the catalytic activity of the Ru-based catalysts. All the related catalysts exhibited selectivity to VCM of over $99.0 \%$ during the $24 \mathrm{~h}$ reaction (Fig. 1b). Moreover, compared with the other noble metal (Au, Pd) catalysts, Ru-based catalysts enjoy a cost advantage; they also have higher activity and a lower deactivation rate than those of the nonmetallic catalysts (Table S1†). Thus, the results indicate that the economical $\mathrm{Ru}-\mathrm{O} / \mathrm{AC}-\mathrm{O}$ catalyst could give favorable performance and that the catalyst may be promising for future applications.

\subsection{FT-IR spectra of the Ru-based catalysts}

FT-IR spectra were obtained to study the surface functional groups of the catalysts. The spectra of the AC, AC-O, and fresh and used Ru-based catalysts are shown in Fig. 2. For the fresh AC, six characteristic peaks appear at 806, 1091, 1384, 1562, 2350 , and $3400 \mathrm{~cm}^{-1}$, related to the $\mathrm{C}-\mathrm{H}$ bending vibration band on the benzene ring, $\mathrm{C}-\mathrm{OH}$ absorption band, $\mathrm{C}=\mathrm{O}$ absorption band, $\mathrm{COOH}$ antisymmetric stretching vibration band, $\mathrm{C} \equiv \mathrm{N}$ stretching vibration band, and phenolic hydroxyl 
stretching vibration band, respectively. ${ }^{33-35}$ Compared with the AC catalyst, the intensity of the $\mathrm{C}-\mathrm{H}$ bending vibration band on the benzene ring is reduced and that of the $\mathrm{C}-\mathrm{OH}$ absorption band and $\mathrm{C} \equiv \mathrm{N}$ stretching vibration band are increased in the $\mathrm{AC}-\mathrm{O}$ catalyst, indicating that the functional groups on the AC surface were successfully modified to a certain degree by nitric acid treatment. This can increase the hydrophilicity of the AC surface so as to improve the dispersion of the active component on its surface. For the fresh Ru-based catalysts, the $\mathrm{C} \equiv \mathrm{N}$ stretching vibration band has disappeared and the intensities of the oxygenated functional groups are also decreased to a different degree. It is worth mentioning that there are marked red-shifts of some oxygenated functional groups, especially for the $\mathrm{C}-\mathrm{OH}$ absorption bands. This may be caused by the interaction between the oxygenated functional groups on the AC surface and the Ru species. For the used catalysts after experiencing a $24 \mathrm{~h}$ reaction, the $\mathrm{C} \equiv \mathrm{N}$ stretching vibration band has disappeared for the AC-O catalyst, while the intensities of the functional groups on the surface are decreased (take $\mathrm{Ru} / \mathrm{AC}$ for example, Fig. S2 $\dagger$ ). This may be caused by the decomposition of the oxygenated functional groups on the surface or the coke deposition during the reaction.

\subsection{Texture properties of the catalysts}

Low-temperature $\mathrm{N}_{2}$ adsorption/desorption experiments were conducted to measure the pore structure parameters of the catalysts. AC and AC-O presented type-I isotherms due to the
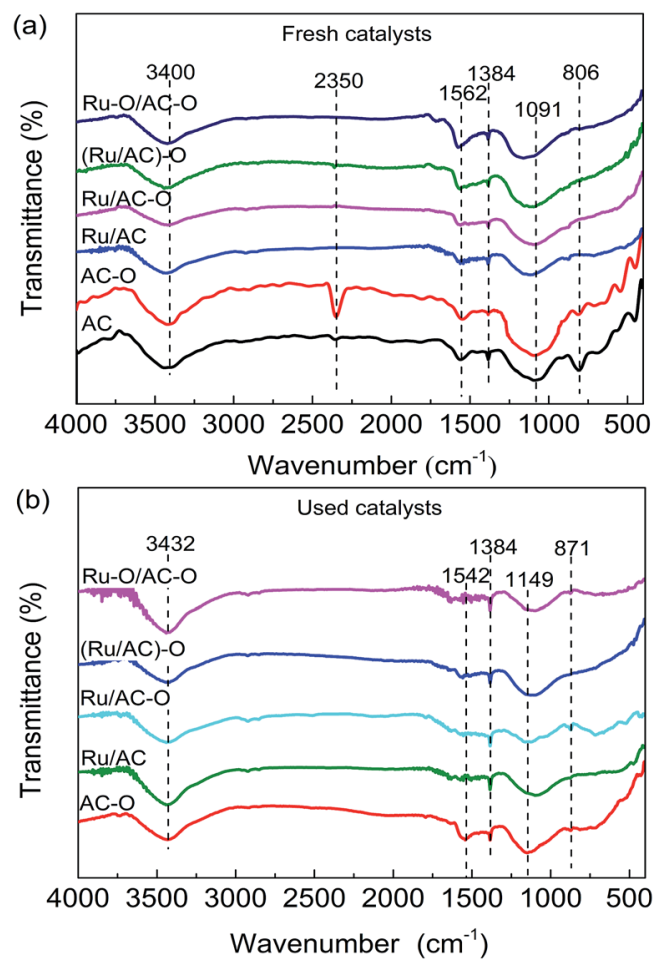

Fig. 2 FT-IR spectra of the (a) fresh catalysts and (b) used catalysts. The characteristic peaks are centered at: $806 \mathrm{~cm}^{-1}: \mathrm{C}-\mathrm{H} ; 1091 \mathrm{~cm}^{-1}$. $\mathrm{C}-\mathrm{OH} ; 1384 \mathrm{~cm}^{-1}: \mathrm{C}=\mathrm{O} ; 1562 \mathrm{~cm}^{-1}: \mathrm{COOH} ; 2350 \mathrm{~cm}^{-1}: \mathrm{C} \equiv \mathrm{N}$; and $3400 \mathrm{~cm}^{-1}$ : phenolic hydroxyl. adsorption in the micro-pores. ${ }^{31}$ The fresh and used Ru-based catalysts exhibited similar adsorption isotherms (Fig. S3 $\dagger$ ).

Table 1 lists the pore structure parameters of the Ru-based catalysts. $\mathrm{Ru} / \mathrm{AC}$ and $\mathrm{Ru} / \mathrm{AC}-\mathrm{O}$ exhibit BET surface areas and total pore volumes lower than that of $\mathrm{AC}$ and $\mathrm{AC}-\mathrm{O}$. This was due to the loading of active metallic components, mentioned as the dilution effect previously. ${ }^{36}$ The BET surface area and pore volume of fresh $\mathrm{AC}-\mathrm{O}$ are lower than those of bare $\mathrm{AC}$, the fresh $\mathrm{Ru} / \mathrm{AC}-\mathrm{O},(\mathrm{Ru} / \mathrm{AC})-\mathrm{O}$, and $\mathrm{Ru}-\mathrm{O} / \mathrm{AC}-\mathrm{O}$ catalysts show lower BET surface areas and pore volumes than those of $\mathrm{Ru} / \mathrm{AC}$, probably due to the functional groups being successfully grafted onto the surface of carrier and the pores becoming occupied after the modification. Compared with the fresh Ru-based catalysts, the used catalysts exhibit lower BET surface areas and total pore volumes (Table 1). For the used AC-O catalyst after a $24 \mathrm{~h}$ reaction, the BET surface area is decreased from $1082 \mathrm{~m}^{2} \mathrm{~g}^{-1}$ to $1031 \mathrm{~m}^{2} \mathrm{~g}^{-1}$, a reduction of $4.7 \%$. The surface area of the used $\mathrm{Ru} / \mathrm{AC}$ catalyst is decreased from $978 \mathrm{~m}^{2} \mathrm{~g}^{-1}$ to $768 \mathrm{~m}^{2} \mathrm{~g}^{-1}$, for a reducing fraction of $21.4 \%$. Similarly, the surface areas of the used $\mathrm{Ru} / \mathrm{AC}-\mathrm{O}$, ( $\mathrm{Ru} / \mathrm{AC})-\mathrm{O}$, and $\mathrm{Ru}-\mathrm{O} / \mathrm{AC}-\mathrm{O}$ catalysts show reducing fractions of $16.3 \%, 15.8 \%$, and $8.1 \%$, respectively. The change in the pore volume of the catalysts also exhibits a similar order: $\mathrm{Ru} / \mathrm{AC}(28.8 \%)>\mathrm{Ru} / \mathrm{AC}-\mathrm{O}(20.8 \%)>(\mathrm{Ru} / \mathrm{AC})-\mathrm{O}(18.0 \%)>$ $\mathrm{Ru}-\mathrm{O} / \mathrm{AC}-\mathrm{O}(13.2 \%)>\mathrm{AC}-\mathrm{O}(1.9 \%)$. Compared with $\mathrm{AC}-\mathrm{O}$, the obvious decrease in BET surface areas and the total pore volumes of the Ru-based catalysts may due to the metalcatalyzed reaction. ${ }^{37}$ The loss of surface areas and pore volumes may also be due to the collapse of the pores and the deposition of coke on the surface of the catalysts. According to the catalytic activity shown in Fig. 1, the initial conversion of acetylene is $78.6 \%$ over $\mathrm{Ru} / \mathrm{AC}, 93.0 \%$ over $\mathrm{Ru} / \mathrm{AC}-\mathrm{O}, 99.3 \%$ over $(\mathrm{Ru} / \mathrm{AC})-\mathrm{O}$, and $99.6 \%$ over $\mathrm{Ru}-\mathrm{O} / \mathrm{AC}-\mathrm{O}$, which are then decreased respectively to $60.9 \%, 80.0 \%, 84.3 \%$, and $91.6 \%$ after $24 \mathrm{~h}$ reaction. Therefore, it can be reasonably considered that the decrease in the BET surface areas and total pore volumes may be due to the collapse of the pores and the deposition of coke on the surface for the used catalysts during the reaction, resulting in the observed decreases in the catalytic activity. ${ }^{37}$

\subsection{Coke deposition on the catalyst surface}

The TGA curves of the Ru-based catalysts were recorded to analyze the coke deposition on the used catalysts. As shown in

Table 1 Pore structure parameters of the fresh and used Ru-based catalysts

\begin{tabular}{llllll}
\hline & \multicolumn{2}{l}{$\begin{array}{l}\text { Surface area } \\
\left(\mathrm{m}^{2} \mathrm{~g}^{-1}\right)\end{array}$} & & \multicolumn{2}{l}{$\begin{array}{l}\text { Total pore volume } \\
\left(\mathrm{cm}^{3} \mathrm{~g}^{-1}\right)\end{array}$} \\
\cline { 2 - 3 } Catalyst & Fresh & Used & & Fresh & Used \\
\hline $\mathrm{AC}$ & 1146 & - & & 0.57 & - \\
$\mathrm{AC}-\mathrm{O}$ & 1082 & 1031 & & 0.54 & 0.53 \\
$\mathrm{Ru} / \mathrm{AC}$ & 978 & 768 & & 0.52 & 0.37 \\
$\mathrm{Ru} / \mathrm{AC}-\mathrm{O}$ & 936 & 783 & & 0.48 & 0.38 \\
$(\mathrm{Ru} / \mathrm{AC})-\mathrm{O}$ & 942 & 793 & & 0.50 & 0.41 \\
$\mathrm{Ru}-\mathrm{O} / \mathrm{AC}-\mathrm{O}$ & 963 & 885 & & 0.53 & 0.46
\end{tabular}




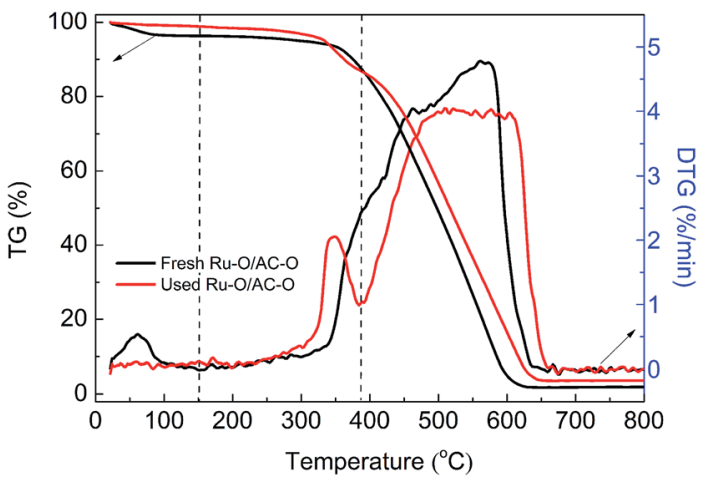

Fig. 3 TG curves of the fresh and used Ru-O/AC-O catalysts recorded under an air atmosphere.

Table 2 The amount of coke deposition on the used catalysts

\begin{tabular}{ll}
\hline Samples & $\begin{array}{l}\text { Amount of coke } \\
\text { deposition (\%) }\end{array}$ \\
\hline $\mathrm{AC}-\mathrm{O}$ & 2.1 \\
$\mathrm{Ru} / \mathrm{AC}$ & 7.5 \\
$\mathrm{Ru} / \mathrm{AC}-\mathrm{O}$ & 5.6 \\
$(\mathrm{Ru} / \mathrm{AC})-\mathrm{O}$ & 5.1 \\
$\mathrm{Ru}-\mathrm{O} / \mathrm{AC}-\mathrm{O}$ & 3.7
\end{tabular}

Fig. 3, there is a slight weight loss in the range of ambient temperature to $150{ }^{\circ} \mathrm{C}$ for the fresh and used $\mathrm{Ru}-\mathrm{O} / \mathrm{AC}-\mathrm{O}$ catalyst, which is attributed to the desorption of adsorbed water on the surface of the catalysts. In the temperature range of 150$385{ }^{\circ} \mathrm{C}$, both the fresh and used catalysts exhibit a slow weight loss, where the amount in the used catalyst is higher than that in the fresh catalyst, which could mainly be due to the burning of coke deposition after experiencing the $24 \mathrm{~h}$ reaction. When the temperature is greater than $385{ }^{\circ} \mathrm{C}$, the catalysts show a rapid weight loss, which is mainly attributed to the burning of AC itself. Therefore, the amount of coke deposition could be calculated by the difference in weight loss of the fresh and used $\mathrm{Ru}-\mathrm{O} / \mathrm{AC}-\mathrm{O}$ catalyst in the temperature range of $150-385{ }^{\circ} \mathrm{C} .3^{88-40}$ Based on Fig. 3, the amount of coke deposition during the reaction was calculated as $3.6 \%$.

According to similar procedures, the extent of coke deposition on the other used catalysts was calculated (Fig. S4 $\dagger$ and Table 2) and the amount of coke deposition on all the used catalysts increases in the order: AC-O $(2.1 \%)<\mathrm{Ru}-\mathrm{O} / \mathrm{AC}-\mathrm{O}$ $(3.7 \%)<(\mathrm{Ru} / \mathrm{AC})-\mathrm{O}(5.1 \%)<\mathrm{Ru} / \mathrm{AC}-\mathrm{O}(5.6 \%)<\mathrm{Ru} / \mathrm{AC}(7.5 \%)$, which is consistent with the results of the low-temperature $\mathrm{N}_{2}$ adsorption-desorption experiments. Thus, it is reasonable to conclude that coke deposition during the reaction is one of the reasons for the catalysts deactivation and also that the oxidation modification is beneficial for the inhibition of coke deposition during the reaction.

\subsection{Reducibility of the fresh Ru-based catalysts}

Fig. 4 shows the TPR profiles of the fresh catalysts. There appears broad peaks for all the catalysts in the range of 500-
$700{ }^{\circ} \mathrm{C}$, which is attributed to the methanation of the functional groups on the carrier. ${ }^{41,42}$ There are also several $\mathrm{H}_{2}$ consumption peaks in the range of $100-400{ }^{\circ} \mathrm{C}$ for the Ru-based catalysts because of the existence of oxidation state ruthenium species. For the TPR profile of the $\mathrm{Ru} / \mathrm{AC}$ catalyst, there are three reduction peaks centered at $150.3{ }^{\circ} \mathrm{C}, 250.7{ }^{\circ} \mathrm{C}$, and $323.7^{\circ} \mathrm{C}$, which correspond to the characteristic reduction peaks of $\mathrm{RuO}_{x}$ $(x>2), \mathrm{RuO}_{2}$, and $\mathrm{RuCl}_{3}$, respectively. ${ }^{32}$ However, the oxidation modification slightly increases the reduction temperatures for $\mathrm{RuO}_{x}$ and $\mathrm{RuO}_{2}$ and decreases the reduction temperatures for the $\mathrm{RuCl}_{3}$ species. For the $\mathrm{Ru} / \mathrm{AC}-\mathrm{O}$ catalyst, the reduction temperatures for $\mathrm{RuO}_{x}$ and $\mathrm{RuO}_{2}$ increase to $156.3{ }^{\circ} \mathrm{C}$ and $257.2^{\circ} \mathrm{C}$, respectively, and the reduction temperatures for $\mathrm{RuCl}_{3}$ decreases to $312.8^{\circ} \mathrm{C}$. For the (Ru/AC)-O catalyst, the reduction temperatures for $\mathrm{RuO}_{x}$ and $\mathrm{RuO}_{2}$ increase to $175.3{ }^{\circ} \mathrm{C}$ and $260.3{ }^{\circ} \mathrm{C}$, respectively, and the reduction temperature for $\mathrm{RuCl}_{3}$ decreases to $305.6{ }^{\circ} \mathrm{C}$. The $\mathrm{Ru}-\mathrm{O} / \mathrm{AC}-\mathrm{O}$ catalyst exhibits a similar curve to that of $(\mathrm{Ru} / \mathrm{AC})-\mathrm{O}$, with the peak temperatures for $\mathrm{RuO}_{x}$ and $\mathrm{RuO}_{2}$ shifted to higher values $\left(183.4{ }^{\circ} \mathrm{C}\right.$ and $266.9^{\circ} \mathrm{C}$ for $\mathrm{RuO}_{x}$ and $\mathrm{RuO}_{2}$, respectively). These shifts indicate interactions between the active Ru species and carrier, which is consistent with the FT-IR results. Furthermore, the amount of $\mathrm{Ru}$ oxides $\left(\mathrm{RuO}_{x}\right.$ and $\left.\mathrm{RuO}_{2}\right)$ decreases in the order: $\mathrm{Ru}-\mathrm{O} / \mathrm{AC}-\mathrm{O}$ $>(\mathrm{Ru} / \mathrm{AC})-\mathrm{O}>\mathrm{Ru} / \mathrm{AC}-\mathrm{O}>\mathrm{Ru} / \mathrm{AC}$ (Fig. 4), which is consistent with the activity results of the Ru-based catalysts. This indicates that the oxidation modification leads to a larger amount of $\mathrm{Ru}$ oxides, thereby improving the catalytic performance of the catalysts.

To further study the effects of oxidation modification on the active Ru species for acetylene hydrochlorination, Ru 3p3/2 XPS spectra of all the Ru-based catalysts were obtained (Fig. S5 and Table S2 $\uparrow$ ), and the binding energies and relative quantities are shown in Table 3. For all the Ru-based catalysts, the Ru 3p3/2 XPS spectra could be deconvoluted into three to five peaks at ca. 460.8, 461.9, 463.5, 465.2, and $466.4 \mathrm{eV}$, which correspond to $\mathrm{Ru}^{0}, \mathrm{Ru} / \mathrm{RuO}_{y}, \mathrm{RuCl}_{3}, \mathrm{RuO}_{2}$, and $\mathrm{RuO}_{x}$, respectively. ${ }^{32,43,44}$ As shown in Table 3, Ru/AC consists of $25.2 \% \mathrm{Ru}^{0}, 35.7 \% \mathrm{RuCl}_{3}$, $24.4 \% \mathrm{RuO}_{2}$, and $14.7 \% \mathrm{RuO}_{x}$. The modified Ru/AC-O catalyst contains $26.4 \% \mathrm{Ru}^{0}, 33.9 \% \mathrm{RuCl}_{3}, 26.4 \% \mathrm{RuO}_{2}$, and $13.3 \%$ $\mathrm{RuO}_{x}$. The dominant species in ( $\left.\mathrm{Ru} / \mathrm{AC}\right)-\mathrm{O}$ is $34.3 \% \mathrm{RuCl}_{3}$,

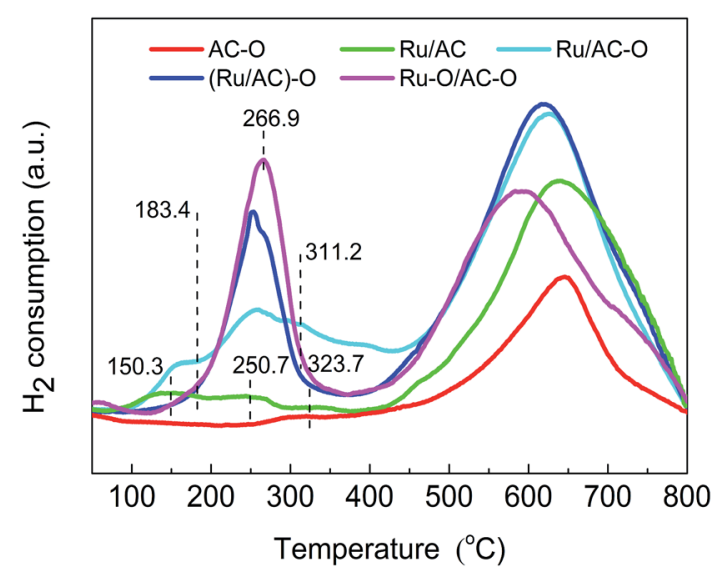

Fig. $4 \mathrm{H}_{2}$-TPR profiles of the fresh $\mathrm{Ru}$-based catalysts. 
Table 3 Relative content and binding energy of ruthenium species in the fresh and used catalysts

\begin{tabular}{|c|c|c|c|c|c|c|}
\hline Catalysts & \multicolumn{5}{|c|}{ Binding energy (eV), (area\%) } & $\frac{\text { Area\% }}{\mathrm{RuO}_{x}+\mathrm{RuO}_{2}}$ \\
\hline Used Ru/AC & - & $465.0(20.5)$ & $463.7(32.4)$ & - & $460.8(47.1)$ & $(20.5)$ \\
\hline Fresh $\mathrm{Ru} / \mathrm{AC}-\mathrm{O}$ & $467.1(13.3)$ & $465.3(26.4)$ & $463.5(33.9)$ & - & $460.7(26.4)$ & $(39.7)$ \\
\hline Used $\mathrm{Ru} / \mathrm{AC}-\mathrm{O}$ & - & $464.9(26.1)$ & $463.4(37.8)$ & $462.0(36.1)$ & - & $(26.1)$ \\
\hline Fresh $\mathrm{Ru}-\mathrm{O} / \mathrm{AC}-\mathrm{O}$ & $467.4(24.7)$ & $465.1(36.5)$ & $463.4(25.1)$ & $461.8(13.7)$ & - & $(61.2)$ \\
\hline Used $\mathrm{Ru}-\mathrm{O} / \mathrm{AC}-\mathrm{O}$ & $467.2(30.2)$ & $465.4(29.6)$ & $463.8(24.3)$ & $461.8(15.9)$ & - & $(59.8)$ \\
\hline
\end{tabular}

followed by $26.1 \% \mathrm{RuO}_{2}, 22.8 \% \mathrm{RuO}_{x}$, and $16.8 \% \mathrm{Ru} / \mathrm{RuO}_{y}$. $\mathrm{Ru}-$ $\mathrm{O} / \mathrm{AC}-\mathrm{O}$ contains $36.5 \% \mathrm{RuO}_{2}$, followed by $24.7 \% \mathrm{RuO}_{x}, 25.1 \%$ $\mathrm{RuCl}_{3}$, and $13.7 \% \mathrm{Ru} / \mathrm{RuO}_{y}$. The amount of $\mathrm{Ru}$ oxides $\left(\mathrm{RuO}_{2}\right.$ and $\mathrm{RuO}_{x}$ ) decreases in the order: $\mathrm{Ru}-\mathrm{O} / \mathrm{AC}-\mathrm{O}(61.2 \%)>(\mathrm{Ru} / \mathrm{AC})-\mathrm{O}$ $(48.9 \%)>\mathrm{Ru} / \mathrm{AC}-\mathrm{O}(39.7 \%)>\mathrm{Ru} / \mathrm{AC}$ (39.1\%). According to the previous literature, $\mathrm{Ru}$ oxides are the dominant active species in Ru-based catalysts. ${ }^{31,32}$ The oxidation modification results in a higher quantity of high-valence Ru oxides in the fresh catalysts, which is consistent with the TPR results. Moreover, binding energy shifts for the ruthenium species were observed upon oxidation modification, confirming the interactions between the Ru species and the carrier. For the used catalysts, the $\mathrm{Ru}$ oxides $\left(\mathrm{RuO}_{2}\right.$ and $\left.\mathrm{RuO}_{x}\right)$ content of $\mathrm{Ru} / \mathrm{AC}$ decreases to $20.5 \%$ with a $47.6 \%$ loss of active species, whereas there are $34.3 \%, 31.1 \%$, and $2.3 \%$ losses of active species for the oxidized $\mathrm{Ru} / \mathrm{AC}-\mathrm{O}$, ( $\mathrm{Ru} / \mathrm{AC})-\mathrm{O}$, and $\mathrm{Ru}-\mathrm{O} / \mathrm{AC}-\mathrm{O}$ catalysts, respectively. It has been reported that the reduction of Ru oxides to low-valence $\mathrm{Ru}$ species results in the deactivation of Ru-based catalysts; ${ }^{32}$ therefore, it can be concluded that the oxidation modification of the catalysts inhibits the reduction of ruthenium oxides to lowvalence $\mathrm{Ru}$ species in the processes of catalyst preparation and reaction. Fig. S6† shows the C1s XPS spectra of fresh AC, AC-O, $\mathrm{Ru} / \mathrm{AC}, \mathrm{Ru} / \mathrm{AC}-\mathrm{O}$, (Ru/AC)-O, and $\mathrm{Ru}-\mathrm{O} / \mathrm{AC}-\mathrm{O}$. Major peaks appear at $c a$. 288.9, 287.1, 285.9, and $284.6 \mathrm{eV}$, corresponding to carboxylic groups, carbonyl groups, hydroxyl groups, and carbon groups, respectively. ${ }^{21}$ The relevant C1s peak areas and binding energies are shown in Table 4. Compared with

Table 4 Relative content and binding energy of carbon species in the fresh catalysts

\begin{tabular}{lllll}
\hline \multicolumn{5}{c}{ Binding energy $(\mathrm{eV}),($ area\%) } \\
\cline { 2 - 5 } Catalysts & $\mathrm{COOH}$ & $\mathrm{C}=\mathrm{O}$ & $\mathrm{C}-\mathrm{OH}$ & $\mathrm{C}-\mathrm{C}$ \\
\hline Fresh AC & $288.7(8.30)$ & $287.1(6.70)$ & $285.8(19.4)$ & $284.6(65.6)$ \\
Fresh AC-O & $288.9(8.80)$ & $287.1(8.50)$ & $285.9(23.3)$ & $284.6(59.4)$ \\
Fresh Ru/AC & $288.9(8.00)$ & $287.5(7.30)$ & $286.2(15.3)$ & $284.6(69.4)$ \\
Fresh & $288.9(7.90)$ & $287.4(10.4)$ & $286.2(16.1)$ & $284.6(65.6)$ \\
Ru/AC-O & & & & \\
Fresh & $289.3(6.20)$ & $287.1(13.9)$ & $286.1(17.4)$ & $284.6(62.5)$ \\
$\begin{array}{l}\text { Ru/AC)-O } \\
\text { Fresh }\end{array}$ & $288.9(11.0)$ & $286.8(13.9)$ & $285.8(15.6)$ & $284.6(59.5)$ \\
Ru-O/AC-O & & & &
\end{tabular}

AC and AC-O, the hydroxyl, carbonyl, and carboxyl groups of AC-O are increased to a certain extent, and the increase in the hydroxyl group is the largest. For the fresh Ru-based catalysts, $\mathrm{Ru}-\mathrm{O} / \mathrm{AC}-\mathrm{O}$ has the highest content of oxygenated functional groups. The increase in oxygenated functional groups may play a role in the immobilization of $\mathrm{Ru}$ active species.

\subsection{Adsorption of reactants on the Ru-based catalysts}

TPD experiments were conducted to investigate the adsorption of hydrogen chloride and acetylene by the fresh catalysts. The HCl- and $\mathrm{C}_{2} \mathrm{H}_{2}$-TPD profiles of the different catalysts are shown
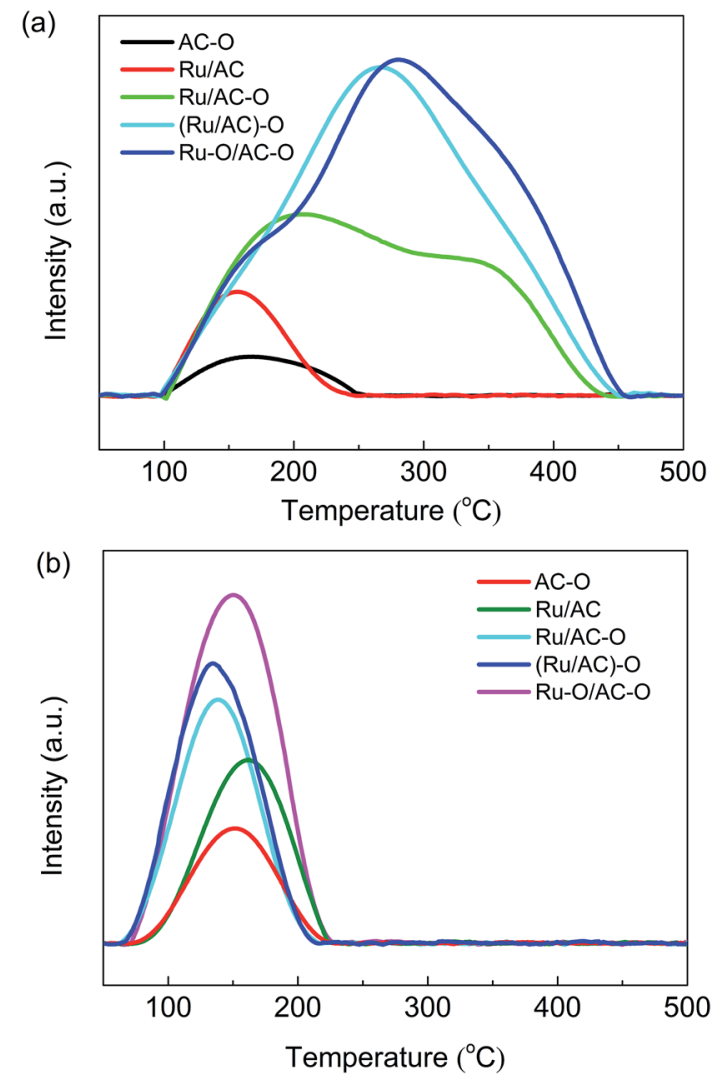

Fig. $5 \mathrm{HCl}-(\mathrm{a})$ and $\mathrm{C}_{2} \mathrm{H}_{2}-$ (b) TPD profiles of the catalysts. 
in Fig. 5. The desorption peaks for $\mathrm{HCl}$ are shown as broad bands in the temperature range of $100-500{ }^{\circ} \mathrm{C}$ for the catalysts (Fig. 5a), suggesting the presence of multi-status adsorbed $\mathrm{HCl}^{16}$ The desorption area for $\mathrm{HCl}$ gradually increases in the order: $\mathrm{AC}-\mathrm{O}<\mathrm{Ru} / \mathrm{AC}<\mathrm{Ru} / \mathrm{AC}-\mathrm{O}<(\mathrm{Ru} / \mathrm{AC})-\mathrm{O}<\mathrm{Ru}-\mathrm{O} / \mathrm{AC}-\mathrm{O}$. The desorption temperature for $\mathrm{HCl}$ also increases in the same order, indicating that the oxidation modification enhances the adsorption of the reactant $\mathrm{HCl}$. The $\mathrm{Ru}-\mathrm{O} / \mathrm{AC}-\mathrm{O}$ catalyst exhibits the best adsorption capacity and strength for $\mathrm{HCl}$. The desorption peaks for acetylene are centered at $\mathrm{ca} .150^{\circ} \mathrm{C}$ for all the catalysts (Fig. 5b), and the desorption area of acetylene also decreases in the order: $\mathrm{Ru}-\mathrm{O} / \mathrm{AC}-\mathrm{O}>(\mathrm{Ru} / \mathrm{AC})-\mathrm{O}>\mathrm{Ru} / \mathrm{AC}-\mathrm{O}>$ $\mathrm{Ru} / \mathrm{AC}>\mathrm{AC}-\mathrm{O}$. Thus, it is reasonable to assume that oxidation modification of the AC support and the active component
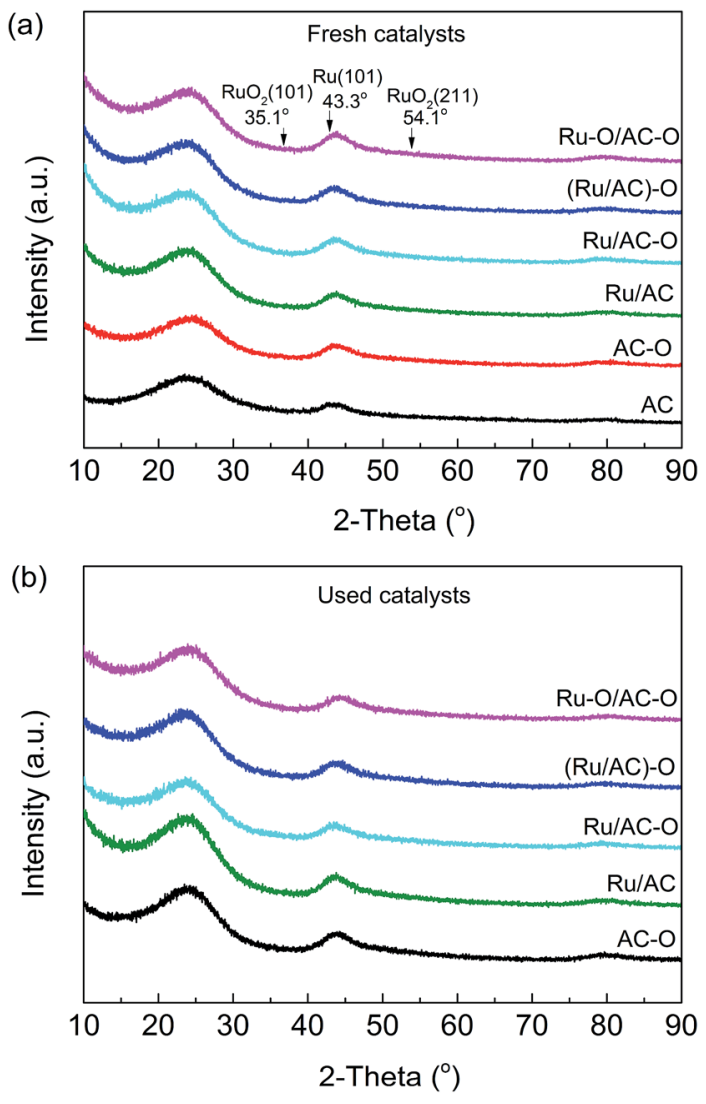

Fig. 6 XRD patterns of the fresh (a) and used (b) catalysts. greatly enhances the adsorption ability of the catalyst for both $\mathrm{HCl}$ and acetylene.

\subsection{Dispersion of $\mathrm{Ru}$ particles}

Fig. 6 shows the XRD patterns of the fresh and used Ru-based catalysts. The amorphous diffraction peaks for carbon are clearly apparent; however, no discernible $\mathrm{Ru}$ reflections are detected for the fresh and used catalysts, indicating the high dispersion $(<4 \mathrm{~nm})$ and/or the amorphous state of the active species, which is consistent with the TEM images (Fig. S7 $\dagger$ and Table 5).

Further, CO-TPD experiments were carried out to estimate the dispersion of $\mathrm{Ru}$ species. As shown in Table 5, the $\mathrm{Ru}$ dispersion is $25.4 \%$ for $\mathrm{Ru} / \mathrm{AC}$, and then increases after the oxidation modification of the catalysts. The highest dispersion of $34.3 \%$ is achieved in the $\mathrm{Ru}-\mathrm{O} / \mathrm{AC}-\mathrm{O}$ catalyst, followed by $(\mathrm{Ru} / \mathrm{AC})-\mathrm{O}(30.2 \%)$ and $\mathrm{Ru} / \mathrm{AC}-\mathrm{O}(27.7 \%)$. In combination with the XRD patterns and TEM images, these data indicate that in all likelihood the oxidation modification increases the hydrophilicity of the AC surface, thus improving the dispersion of the active Ru species on its surface, which is consistent with the FTIR results.

\subsection{Recycling Ru-based catalysts}

$\mathrm{Ru}-\mathrm{O} / \mathrm{AC}-\mathrm{O}$ was chosen as the catalyst to assess the reusability of the $\mathrm{Ru}$-based catalysts. The used $\mathrm{Ru}-\mathrm{O} / \mathrm{AC}-\mathrm{O}$ catalyst $(0.96 \mathrm{~g}$ )

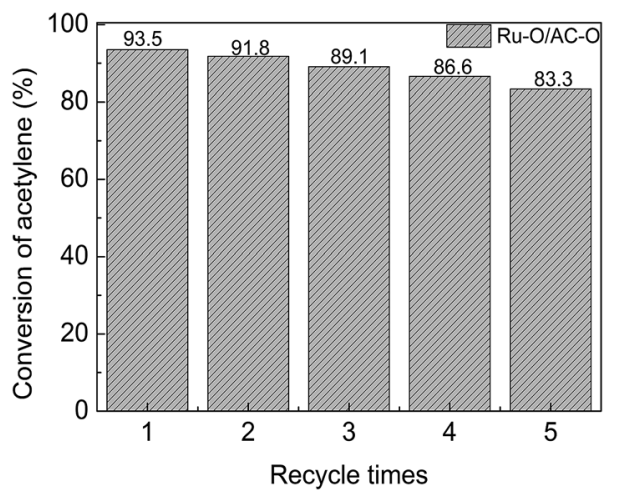

Fig. 7 Catalytic performance of the recycled $\mathrm{Ru}-\mathrm{O} / \mathrm{AC}-\mathrm{O}$ catalysts. Reaction conditions: temperature $=180^{\circ} \mathrm{C}, \mathrm{GHSV}\left(\mathrm{C}_{2} \mathrm{H}_{2}\right)=180 \mathrm{~h}^{-1}$, and $V_{\mathrm{HCl}} / V_{\mathrm{C}_{2} \mathrm{H}_{2}}=1.15: 1$.

Table 5 Average size of Ru particles in the Ru-based catalysts

\begin{tabular}{|c|c|c|c|c|c|}
\hline Catalysts & $\begin{array}{l}\text { Ru loading }{ }^{a} \\
\text { (wt\%) }\end{array}$ & $\begin{array}{l}\text { CO uptake }(\mu \mathrm{mol} \\
\text { CO per g) }\end{array}$ & $\begin{array}{l}\text { Ru dispersion } \\
(\%)\end{array}$ & $\begin{array}{l}\text { Average size of } \\
\text { Ru particles }{ }^{b}(\mathrm{~nm})\end{array}$ & $\begin{array}{l}\text { Average size of } \\
\text { Ru particles }{ }^{c}(\mathrm{~nm})\end{array}$ \\
\hline $\mathrm{Ru} / \mathrm{AC}$ & 0.913 & 17.5 & 19.4 & 3.91 & 5.21 \\
\hline (Ru/AC)-O & 0.910 & 27.2 & 30.2 & 3.31 & 3.34 \\
\hline $\mathrm{Ru}-\mathrm{O} / \mathrm{AC}-\mathrm{O}$ & 0.915 & 31.0 & 34.3 & 2.97 & 2.94 \\
\hline
\end{tabular}

${ }^{a}$ Note: the actual Ru loading determined by ICP. ${ }^{b}$ Average size of Ru particles determined via TEM. ${ }^{c}$ Average size of Ru particles calculated by $101 /$ Ru dispersion. 
was taken into a beaker, then $6.4 \mathrm{~mL}$ nitric acid $\left(0.94 \mathrm{~mol} \mathrm{~L}^{-1}\right)$ solution was added; the mixture was stirred at ambient temperature for $5 \mathrm{~h}$, then filtered and washed to neutral $\mathrm{pH}$ with deionized water, followed by desiccation at $140{ }^{\circ} \mathrm{C}$ for $18 \mathrm{~h}$. The obtained catalyst was reused to catalyze the acetylene hydrochlorination reaction for $24 \mathrm{~h}$. Fig. 7 shows the activity of the recycled catalysts. It can be seen from Fig. 7 that a stable acetylene conversion of $93.5 \%$ could be achieved over the fresh catalyst in the first run. After recycling 5 times, the conversion of acetylene was still able to return to $83.3 \%$. As mentioned, the deactivation of the catalyst was mainly due to coke deposition and the reduction of the active component during the reaction. Coke deposition may be partially removed and the reduced $\mathrm{Ru}$ species may be oxidized to a high state of active species to some extent by treatment with nitric acid in the regeneration of $\mathrm{Ru}-\mathrm{O} /$ AC-O, thereby improving the catalytic performance of the used catalyst.

\section{Conclusions}

Several Ru-based catalysts were prepared by different oxidation modification procedures and assessed for acetylene hydrochlorination. Modification of the active species and the carrier by $\mathrm{HNO}_{3}$ was shown to be beneficial for acetylene hydrochlorination, whereby the optimal catalytic performance was achieved over the $\mathrm{Ru}-\mathrm{O} / \mathrm{AC}-\mathrm{O}$ catalyst with an initial $\mathrm{C}_{2} \mathrm{H}_{2}$ conversion of $99.6 \%$ and selectivity to VCM of above $99 \%$ at $180{ }^{\circ} \mathrm{C}$ with a $\mathrm{GHSV}\left(\mathrm{C}_{2} \mathrm{H}_{2}\right)$ of $180 \mathrm{~h}^{-1}$. Through characterization by FT-IR, TGA, TPR, XPS, TPD, XRD, and TEM, it was shown that the appropriate oxidation modification could lead to welldispersed $\mathrm{Ru}$ species and less coke deposition on the surface of catalysts, thereby greatly enhancing the amount of $\mathrm{HCl}$ and $\mathrm{C}_{2} \mathrm{H}_{2}$ reactants adsorbed on the $\mathrm{Ru}$-based catalysts. The enhanced interactions between the active $\mathrm{Ru}$ species and the carrier can stabilize the high-valence state of Ru and inhibit the reduction of high-valence Ru oxides to low-valence species in the processes of the catalyst preparation and during the reaction, consequently enhancing the catalytic activity of the Rubased catalysts.

\section{Acknowledgements}

This work was supported by the Start-Up Foundation for Young Scientists of Shihezi University (RCZX201507), the Program for Changjiang Scholars and Innovative Research Team in University (No. IRT_15R46), and NSFC (U1403294, 21366027).

\section{References}

1 K. Zhou, J. Jia, X. Li, X. Pang, C. Li, J. Zhou, G. Luo and F. Wei, Fuel Process. Technol., 2013, 108, 12-18.

2 G. J. Hutchings, J. Catal., 1985, 96, 292-295.

3 J. Zhang, N. Liu, W. Li and B. Dai, Front. Chem. Sci. Eng., 2011, 5, 514-520.

4 M. Conte, C. J. Davies, D. J. Morgan, T. E. Davies, D. J. Elias, A. F. Carley, P. Johnston and G. J. Hutchings, J. Catal., 2013, 297, 128-136.
5 K. G. Homme, J. K. Kern, B. E. Haley, D. A. Geier, P. G. King, L. K. Sykes and M. R. Geier, BioMetals, 2014, 27, 19.

6 H. Zhang, B. Dai, W. Li, X. Wang, J. Zhang, M. Zhu and J. Gu, J. Catal., 2014, 316, 141-148.

7 X. Wei, H. Shi, W. Qian, G. Luo, Y. Jin and F. Wei, Ind. Eng. Chem. Res., 2009, 48, 128-133.

8 T. V. Krasnyakova, I. V. Zhikharev, R. S. Mitchenko, V. I. Burkhovetski, A. M. Korduban, T. V. Kryshchuk and S. A. Mitchenko, J. Catal., 2012, 288, 33-43.

9 S. Wang, B. Shen and Q. Song, Catal. Lett., 2010, 134, 102109.

10 M. Conte, A. F. Carley, G. Attard, A. A. Herzing, C. J. Kiely and G. J. Hutchings, J. Catal., 2008, 257, 190-198.

11 S. A. Mitchenko, T. V. Krasnyakova and I. V. Zhikharev, Theor. Exp. Chem., 2010, 46, 32-38.

12 M. F. Luo, C. C. Wang, G. R. Hu, W. R. Lin, C. Y. Ho, Y. C. Lin and Y. J. Hsu, J. Phys. Chem. C, 2009, 113, 21054-21062.

13 J. Zhang, W. Sheng, C. Guo and W. Li, RSC Adv., 2013, 3, 21062.

14 M. Zhu, L. Kang, Y. Su, S. Zhang and B. Dai, J. Chem., 2013, 91, 120-125.

15 H. Zhang, B. Dai, X. Wang, L. Xu and M. Zhu, J. Ind. Eng. Chem., 2012, 18, 49-54.

16 H. Zhang, W. Li, X. Li, W. Zhao, J. Gu, X. Qi, Y. Dong, B. Dai and J. Zhang, Catal. Sci. Technol., 2015, 5, 1870-1877.

17 K. Zhou, J. Jia, C. Li, H. Xu, J. Zhou, G. Luo and F. Wei, Green Chem., 2014, 17, 356-364.

18 M. Zhu, Q. Wang, K. Chen, Y. Wang, C. Huang, H. Dai, F. Yu, L. Kang and B. Dai, ACS Catal., 2015, 5, 5306-5316.

19 B. Nkosi, N. J. Coville and G. J. Hutchings, Appl. Catal., 1988, 43, 33-39.

20 J. Zhao, J. Xu, J. Xu, T. Zhang, X. Di, N. I. Jun and X. Li, Chem. Eng. J., 2015, 262, 1152-1160.

21 C. Moreno-Castilla, M. V. López-Ramón and F. CarrascoMaríN, Carbon, 2000, 38, 1995-2001.

22 J. L. Figueiredo, M. F. R. Pereira, M. M. A. Freitas and J. J. M. Órfão, Carbon, 1999, 37, 1379-1389.

23 C. Prado-Burguete, A. Linares-Solano, F. Rodríguez-Reinoso and S. M. D. Lecea, J. Catal., 1989, 115, 98-106.

24 F. J. Derbyshire, V. H. J. D. Beer, G. M. K. Abotsi, A. W. Scaroni, J. M. Solar and D. J. Skrovanek, Appl. Catal., 1986, 27, 117-131.

25 A. Sepúlveda-Escribano, F. Coloma and F. RodríGuezReinoso, Appl. Catal., A, 1998, 173, 247-257.

26 N. Xu, M. Zhu, J. Zhang, H. Zhang and B. Dai, RSC Adv., 2015, 5, 86172-86178.

27 X. Li, X. Pan, L. Yu, P. Ren, X. Wu, L. Sun, F. Jiao and X. Bao, Nat. Commun., 2014, 5, 3688.

28 W. Zhao, W. Li and J. Zhang, Catal. Sci. Technol., 2015, 6, 1402-1409.

29 G. Li, W. Li, H. Zhang, Y. Pu, M. Sun and J. Zhang, RSC Adv., 2014, 5, 9002-9008.

30 Y. Jin, G. Li, J. Zhang, Y. Pu and W. Li, RSC Adv., 2015, 5, 37774-37779.

31 Y. Pu, J. Zhang, L. Yu, Y. Jin, W. Li, Y. Pu, J. Zhang, L. Yu, Y. Jin and W. Li, Appl. Catal., A, 2014, 488, 28-36. 
32 H. Zhang, W. Li, Y. Jin, W. Sheng, M. Hu, X. Wang and J. Zhang, Appl. Catal., B, 2016, 189, 56-64.

33 S. Biniak, G. Szymański, J. Siedlewski and A. Ś. j. m. Tkowski, Carbon, 1997, 35, 1799-1810.

34 N. Brown and H. X. You, Surf. Sci., 1990, 237, 273-279.

35 A. Dandekar, R. T. K. Baker and M. A. Vannice, Carbon, 1998, 36, 1821-1831.

36 H. Zhang, B. Dai, X. Wang, W. Li, Y. Han, J. Gu and J. Zhang, Green Chem., 2013, 15, 829-836.

37 B. Nkosi, N. J. Coville, G. J. Hutchings, M. D. Adams, J. Friedl and F. E. Wagner, J. Catal., 1991, 128, 366-377.

38 F. G. Liu, M. Du, J. Zhang and M. Qiu, Corros. Sci., 2009, 51, 102-109.
39 K. Dumbuya, G. Cabailh, R. Lazzari, J. Jupille, L. Ringel, M. Pistor, O. Lytken, H. P. Steinrück and J. M. Gottfried, Catal. Today, 2012, 181, 20-25.

40 J. K. Brennan, T. J. Bandosz, K. T. Thomson and K. E. Gubbins, Colloids Surf., A, 2001, 187, 539-568.

41 P. D. Zgolicz, J. P. Stassi, M. J. Yañez, O. A. Scelza and S. R. D. Miguel, J. Catal., 2012, 290, 37-54.

42 F. Coloma, A. Sepúlveda-Escribano, J. L. G. Fierro and F. Rodríguez-Reinoso, Appl. Catal., A, 1997, 150, 165-183.

43 J. L. G. D. L. Fuente, M. V. Martínez-Huerta, S. Rojas, P. Hernández-Fernández, P. Terreros, J. L. G. Fierro and M. A. Peña, Appl. Catal., B, 2009, 88, 505-514.

44 J. H. Ma, Y. Y. Feng, J. Yu, D. Zhao, A. J. Wang and B. Q. Xu, J. Catal., 2010, 275, 34-44. 